Plotnick, R.D., et al., 1998. Benefits and costs of a family-focused methadone treatment and drug abuse prevention program: Preliminary findings. In W.J. Bukoski and R.I. Evans (eds.), Cost Benefit/Cost-Effectiveness Research of Drug Abuse Prevention: Implications for Programming and Policy. NIDA Research Monograph 176 (NIH Publication No. 98-4021, pp. 161-183). Rockville, MD: National Institute on Drug Abuse.

Substance Abuse and Mental Health Services Administration (SAMHSA), 2002. Characteristics and needs of the population: Understanding co-occurring disorders. In Report to Congress on the Prevention and Treatment of Co-Occurring Substance Abuse Disorders and Mental Disorders, 2002. www.samhsa.gov/ reports/congress2002/chap1ucod.htm.

SAMHSA, Center for Substance Abuse Treatment (CSAT), 2001. Telling Their Stories: Reflections of the 11 Original Grantees That Piloted Residential Treatment for Women and Children for CSAT. www.samhsa.gov, p. 46.

SAMHSA, CSAT, 2003a. Lessons Learned: Residential Substance Abuse Treatment for Women and Their Children. HHS Publication No. (SMA) 03-0387, p. 26.

SAMHSA, CSAT, 2003b. Services Grant Program for Residential Treatment for Pregnant and Postpartum Women. Short Title: Pregnant and Postpartum Women (PPW). RFA No. TI 03-012, CFDA No. 93.243.

Wegschieder, S., 1981. Another Chance, Hope and Health for the Alcoholic Family. Palo Alto, CA: Science and Behavior Books.

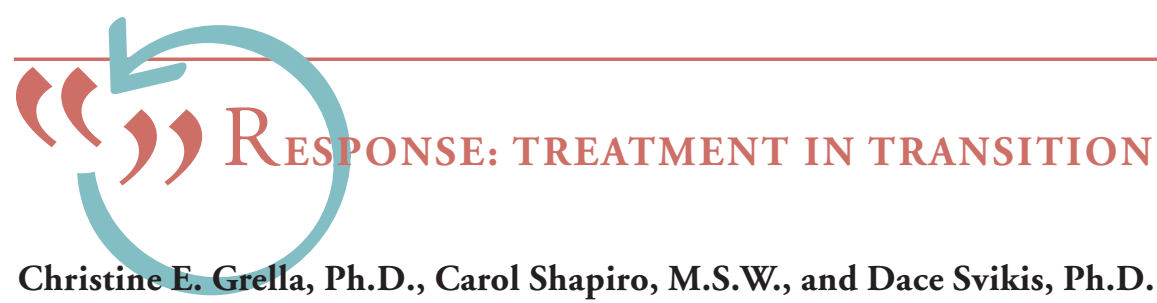

Christine Grella: Jackson's article challenges us to rethink our entire understanding of drug treatment, expand our definition of who is in treatment, and revise our list of desired outcomes. If the family, not the individual with the drug problem, is the unit of treatment, then what counts as success must include whatever contributes to family members' well-being and the way the entire family system functions.

Carol Shapiro: I agree. I was struck by Families in Transition's ecological approach, the way it takes into account the entire context of its clients' lives. Too often, researchers and clinicians tend to isolate people, thinking about them as separate entities and ignoring their personal relationships and connections with their community.

On the other hand, I'm wondering whether the program may actually be limiting in its focus. Its emphasis on case management-on obtaining the right professional services for each child — might lead to a de-emphasis on the children's natural connections with adults other than their parents - the aunts, uncles, and godparents-who may function as their guardians. It's possible that the children's stay in a residential center will weaken or even fracture some of those connections, so that they will need to be repaired when the mother and children leave the program.

Also, residential programs like this are so expensive and the need for treatment is so staggering, that I wonder whether there are more cost-effective ways to support people where they are living. The added benefit of outpatient programs is that the transition out of treatment would be less drastic.

Grella: Actually, I felt that one of the nice features of this program was that its creators have really expanded the concept of family and make it very elastic, to include the aunts and grandmothers.

Dace Svikis: The program is definitely a significant achievement. I operated a residential and intensive outpatient program for pregnant and postpartum drug-dependent women and their children, and I remember what we went through to get our hospital to approve it, and the liability and cost issues we faced.

Grella: I like Jackson's straightforward attitude. She makes it perfectly clear that what she is attempting is fraught with logistical and other practical problems. For one thing, the presence of so many children in the program demands a major commitment of staff resources. Jackson is frank about the fact that the children exhibit serious behavior problems and that safety is a major concern. I think she should be applauded for taking on a real challenge.

\section{Parents' needs and capabilities}

Shapiro: The fact that FIT sets no absolute limit on the number of children a mother can take into treatment with her shows the author's willingness to respect the clients' real needs. 
In my experi-

ence, it is dif-

ficult to work

with more

than two chil-

dren in a fam-

ily in drug

treatment.

Drug-

dependent

women needed

to learn the

basics-how to

hold a baby,

how to change

a diaper-

along with

nurturing

behavior.
Svikis: In my experience, it is difficult to work with more than two children in a family in drug treatment. It comes down to the fact that the mother needs time to focus on herself.

Grella: Mothers themselves are often ambivalent about living with their children. When we conducted an evaluation of an aftercare program for women coming out of prison, we were struck by how many hesitated to reunite, because they realized that their recovery was very fragile. We had to rethink our assumptions about whether and when reunification is desirable.

There is a developing body of research on individuals, male and female, who have children at home when they enter drug treatment. Some studies have found that individuals who are more actively involved in parenting their children do better in treatment. However, we don't know whether this is because individuals who function at a higher level are more able to be involved with their children, or because the children's presence forces the parent to function better.

Shapiro: I look at this question from a slightly different perspective: Public agencies often demonize women who use drugs and make them feel that they are not capable of caring for their children. Staff members should ask people what help they need, not make assumptions about their needs. For this reason, I would like to know more about how the FIT program staff is selected. In particular, do the staff and clients come from the same communities, similar cultural backgrounds? What are they trained in?

Svikis: Many women with substance abuse problems, such as those in the FIT program, lack basic parenting skills. Such women often have lost custody, or others are caring for their children. In my program, the staff found that drug-dependent women needed to learn the basics-how to hold a baby, how to change a diaper-along with nurturing behavior. We need to understand their situations better.

Grella: Yes, we need more research on the parenting capabilities of women in drug treatment.

Another factor here is that there will always be tensions between mothers' and children's needs. Jackson draws attention to some of them. One potential conflict she doesn't mention is between the client's need for other family members and sources of support and the fact that these individuals and institutions may be part of the milieu in which the mother's drug use took place.

Also, the parents' and children's timetables may be at odds, especially when the child welfare system must set deadlines for resolving a child's placement situation. Bringing the parent along in recovery and harmonizing the parent's self- and other-centered needs may take a very long time. It is not clear how to mesh the two timetables.

\section{Matching means to outcomes}

Grella: When I read about the children's progress in FIT, I wasn't surprised, because the program is highly structured and rich in resources. We still need to know what will happen to the children in the longer term. Also, much of what we know pertains to younger children, because research has emphasized pregnancy and prenatal care. We don't know what happens in adolescence.

Shapiro: Yes, we need to take the long view. We need to think about how to establish longer term support networks for families. And we desperately need research that looks at the children's outcomes over the long term.

We also need more research on family support systems. One study by the National Institute of Justice and The Robert Wood Johnson Foundation found that, for some people in outpatient treatment, the family's involvement with the program, not the intensity of the treatment, appeared to determine whether the treatment succeeded.

Grella: I admired the way the program works with the children, using the science-based prevention modules that are out there. I was left wondering, though, how the eclectic mixture of therapies the author mentions are integrated and how the staff is trained in their use. As Jackson states, it would be a worthwhile research project to tease out the various program components and see which are the active ingredients in a family's recovery.

The FIT program's highly unusual joint custody arrangement with the State is intriguing. It provides a built-in incentive for the mothers to stay in the program: to improve their chances of keeping their 
children. We could really use more research on arrangements like this, to learn how to better integrate the various State social services.

Svikis: The problem is that this kind of research is expensive, and random assignment studies are often difficult, if not impossible, to conduct.
Shapiro: There's also a methodological problem. Most current assessment tools evaluate the individual client, not the family. You can't use them to measure changes in family interactions.

What I would most like to see right now is a way we could take this model to the outpatient setting, where so many more people could benefit. $d$ 